\title{
THE CHALLENGES OF ELECTORAL RESEARCH
}

\author{
WARREN E. MILLER \\ University of Michigan
}

D ostwar behavioral research on the electoral process is now entering its fourth decade. From the publication of Lazarsfeld's pioneering work in The People's Choice to the present volume of essays, the domain of electoral studies has made an important contribution to the discipline of political science. For too many years it carried the brunt of the responsibility for advancing the so-called behavioral revolution. In the first instance, it was virtually the only field of political science that responded to the post-World-War-II opportunities to employ new social science methods to create data from real life that were tailored to the interests of the research scholar. The methods and techniques of survey research applied to the study of mass electorates generated new information that, in turn, demanded new analytic techniques and new modes of thought about politically significant phenomena. Whether it was the richness of unorthodox data or the temerity of unorthodox researchers, studies of electoral behavior produced methodological and theoretical dialectics that stimulated a new generation of interest in social inquiry and political science, including political theory. The challenges of Berelson's interpretations in Voting and the definition of new themes of inquiry in The American 
Voter produced an excitement that still characterizes much of the work in the field.

Whether because of the head start provided by the early studies or whether because of the ubiquitous interest in the subject matter, electoral research provides some of the better representations of the cumulative growth of knowledge in the social sciences. One of the more impressive documentations of this conclusion is found in lively contemporary debate in the literature. At least two themes provide the vehicle for controversies over important theoretical developments.

From very early days on, electoral research has been characterized by sustained interest in the crucial watershed phenomena of party realignment. Despite an early, ahistorical perspective, the evolution of a systematic command of the temporal element has widened the scope of these interests. Multiple levels of analysis, ranging from the societal balance of partisan power to the group base of partisan commitment and on to the movitations that move individual voters, have provided a continuing integrative thrust to this domain of social inquiry. In 1975, even more than in 1952, students of electoral behavior comprehend the multiplicity of social, economic, psychological, and political factors that must be embraced across time by any comprehensive understanding of the outcome of the electoral process.

A deep and continuing interest in the public's concern for questions of public policy has led to a complementary but quite distinctive preoccupation with another wide-ranging set of theoretical topics. The role of "issues" in the election campaign has been transformed into a focus on the changing importance of "issue voting" and is now of major importance to the very basic problem of understanding rational choice in social behavior. Social psychologists and mathematical modelers have become as relevant to this domain of inquiry as are the scholars who are intrinsically students of the political process (or vice versa).

The vital excitement of the complementary inquiries into party realignment and issue voting is a testimony to the 
liveliness of this line of research. At the same time, too much of the argument has evolved without the benefit of an equally lively curiosity about the real-world setting in which the argument must ultimately be played out. Students of electoral research have given too little recognition to the fact that their research is mapping a real and changing external world. For one small example, appraisals of macrostatistics concerning the rise of political independence and the decline of party identification have too seldom looked to possible causative changes in the societal condition before moving into powerful interpretations of anticipated political consequences. A partial remedy is supplied by the simple act of taking account of three significant changes that have occurred over the past twenty years.

In the first place, the educational background of the American electorate has been transformed, and that transformation alone could account for some part of the numerical growth of the political independents and the decline of party loyalties. In the second place, the effective implementation of the Voting Rights Act of 1965 brought millions of black citizens into the electoral system, but they came in as political novices, citizens of varying age who were participating in national politics for the first time with all of the lack of anchoring in prior partisan habit and commitment that follows from lack of prior participation. Finally, in 1972 the combination of the slowly changing age distribution of the population and the enfranchisement of citizens between the ages of eighteen and twenty at that point in political history added to the reservoir of politically inexperienced voters who have been eligible to participate in the past two elections.

These three factors by no means account for all of the change in national levels of political partisanship, and they do not argue in any way that the partisanship of the rest of the electorate has not undergone in fact a rather dramatic change. The point is that serious attention to these sources of change would modify many easy assumptions that underlie current theories about partisan dealignment and the voters' rejection of party.

Electoral analysis also has ignored other massive changes that are recognized for their central importance by other lines of 
social inquiry. It seems likely that the impact of television on mass political partisanship has been badly underestimated. Simplistic expectations that dramatic and easily interpretable attributes would be associated with television viewing were not fulfilled. Virtually no research has been designed to capture the cumulative contributions of the television portrayals of the army/McCarthy hearings, the great debates of 1960, the daily carnage of Vietnam, the explosive violence of urban riots and the Democratic convention in Chicago in 1968, or the Watergate trials and impeachment hearings. In analogous fashion, the coming of the age of affluence to a postindustrial society most probably changed many of the basic conditions of mass political reaction and participation as well as the modes of political activity. Students of electoral research had been remarkably remiss in attending to the consequences of affluence, although the economic trauma of 1974-1975 may jar us into a new sensitivity, if not sensibility.

Thinking more exclusively of the world of real politics, we see that there is an irony in the contrast between the work ways of students of electoral research and students of international relations. Events analysis has come to occupy a significant place in the research efforts of the latter, but is almost totally missing from the systematic attention of the former. This is true, despite the fact that the events recorded on television tapes or in newspaper stories most probably have a massive impact on the participants in mass electoral politics and, at least as portrayed in the media, a much more limited, and certainly much more ambiguous, impact on the major actors participating in international relations.

It seems unhappily possible that students of electoral research have been captured too much by the apparently easy fit between the paradigm of experimental design and the data available for analytic manipulation. Thousands of analyses have been generated with party or candidate image, sense of political efficacy or trust in government, or attitudes on issues as the "independent variables" when the real independent variables are the actors and events of the world of politics, external to the 
experimental subjects whose responses constitute the entire basis for data collection.

From a much more parochial perspective, it has been a matter of more than passing interest to follow the discussionsincreasingly frequent and increasingly sharp-of what is often rather loosely called the Michigan or the SRC Model of voting behavior. It may be only because of institutional myopia, but it does seem that too many discussions have been promoted by misunderstandings, often in combination with presumptions that somehow The American Voter was remiss in not giving sufficient prominence to changes in parameter values that have come to pass some ten years after its publication. In any event, and perhaps more to the point, it seems that the major changes of the last twenty years have been more in the external events of the world of politics than in adequacy of the early specification of theoretical requirements for the comprehension of citizens' reactions to those events.

The authors of The American Voter were reasonably restrained in their statement of the theoretical nature of their work. For example, the utilities that were presumed for such ideas as the funnel of causality were quite clearly not confused with those that might have flowed from powerful deductive theory. At times there has been a sense of mild surprise as empirical genearlizations based on data prescribed by "common sense" have come to be designated as important theoretical statements. Although sophisticated methodologists might put the matter differently, if not in disagreement with the continuing perspective of the Michigan group, the Michigan posture has been unabashedly inductive and probably too casual in its articulation of the theoretical potential of many empirical generalizations it has found important. The growing web of interconnected generalizations has tended to satisfy our appetites for theory. Verified failures of replication have been remarkably few, and the extensions have been numerous and rewarding. After becoming accustomed to the inevitable time lag between the release of data to the public domain and the appearance of new research based on those data, we have been 
reassured to the point of genuine gratification to see the extent to which the challenge of innovative extension has been picked up elsewhere. In this volume, in particular, it is a matter of satisfaction to know the extent to which insightful analyses have returned to a deeper scrutiny of party and candidate image materials, or have moved to the extended view made possible by the growing length of the series of studies. The world of the American voter has changed dramatically in twenty years. With perhaps a romantic view that the world is the social scientist's natural laboratory, it seems reasonable to expect that ingenious colleagues will take advantage of that fact, will devise more and more crucial tests of important ideas, and will continue the painstaking elaboration of our shared comprehension of the electoral process. 